\title{
Investigations on crystalline interface within a molecular composite crystal by microscopic techniques
}

\author{
Etienne F.Brès $^{a^{*}}$, Sylvie Ferlay ${ }^{b^{*}}$, Pierre Dechambenoit ${ }^{b}$, Hugues Leroux ${ }^{a}$, Mir Wais \\ Hosseini $^{b^{*}}$, Steve Reyntjens ${ }^{c}$
}

\begin{abstract}
The interface in a composite crystal made by 3-D epitaxial growth of crystalline layers on a seed crystal was studied by both TEM and FIB/STEM microscopies which revealed a diffuse interface between the two isostructural phases extending over $c a 0.7 \mu \mathrm{m}$.
\end{abstract}

\section{Introduction}

Supramolecular chemistry ${ }^{\mathrm{i}}$ and molecular tectonics, ${ }^{\text {ii,iii }}$ have produced recently a large variety of solid state materials with tunable dimensionalities and functional properties ${ }^{\mathrm{iv}}$. In particular, we have designed both 1-D and 2-D H-bonded networks in the crystalline phase by combining cyanometallates anions with bisamidinium cations (fig la) as construction units or tectons ${ }^{\mathrm{v}}$. The interest for growing bulk or patterned crystals is large, since such materials may offer applications in optics and electrooptics or as photorefractive materials. ${ }^{\mathrm{vi}}$ A further step in the processing of such molecular assemblies is the development of crystalline materials involving several crystals. Along this line, we have shown the three-dimensional epitaxial growth of molecular single crystals on single crystals ("crystals of crystals" or composite crystals) from hybrid organic/inorganic species (fig 1b). ${ }^{\text {vii }}$ Indeed, only few examples of molecular composite crystals based on extended coordination polymers and hydrogen bonding have been reported so far in the literature. ${ }^{\text {viii }}$ The formation of interfaces between single crystals is potentially important as many properties such as mechanical, electrical or chemical features can be strongly influenced by the presence of grain boundaries inside the materials and not only by the grains themselves. The success of such an approach would lead to the development of a whole new set of materials. ${ }^{\text {ix }}$

For joining single-crystals, ${ }^{\mathrm{x}}$ different approaches, both at low temperature by sol-gel processes ${ }^{\mathrm{xi}}$ and at high temperature by sintering or plasma deposition, ${ }^{\text {xii }}$ have been reported. Pressure along with high temperature has been also used in order to achieve the bonding between the grains. Dissimilar materials can be joined through a process called "diffusion bonding" by which the surface roughness of both grains before joining can be reduced by voids shrinkage. ${ }^{\text {xiii }}$ However, 
independent of techniques used to join crystals, the main question concerns the nature and understanding of the bonding between grains.

In the present work, we describe the study of an interdiffusion of molecular species, held together by reversible H-bonding and electrostatic interactions, leading to the formation of a crystalline interface by an epitaxial growth and we propose possible mechanisms.

The studied crystalline composite material (Fig. 1) is based on epitaxial growth in solution of $\left[\left(1-2 \mathrm{H}^{+}\right)_{2}-\left(\mathrm{Fe}^{\mathrm{II}}(\mathrm{CN})_{6}{ }^{4-}\right) .8 \mathrm{H}_{2} \mathrm{O}\right]$ (compound $\mathbf{B}$, orange single crystals) on a crystal composed of $\left[\left(1-2 \mathrm{H}^{+}\right)_{2}-\left(\mathrm{Ru}^{\mathrm{II}}(\mathrm{CN})_{6}{ }^{4-}\right) .8 \mathrm{H}_{2} \mathrm{O}\right]$ (compound $\mathbf{A}$, colourless, single crystal) used as seed crystal.

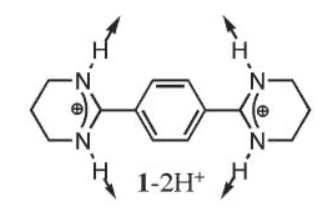

a)

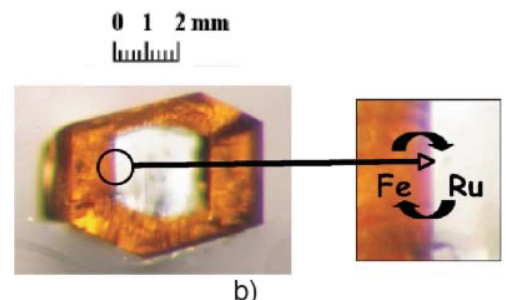

Figure 1

Both crystals of $\left[\left(1-2 \mathrm{H}^{+}\right)_{2}-\left(\mathrm{Fe}^{\mathrm{II}}(\mathrm{CN})_{6}{ }^{4-}\right) .8 \mathrm{H}_{2} \mathrm{O}\right]$ (space group P-1, $a=7.81 \AA, b=11.05 \AA, c=$ $\left.13.46 \AA, \alpha=70.18^{\circ}, \beta=75.21^{\circ}, \gamma=85.10^{\circ}\right)$ and $\left[\left(1-2 \mathrm{H}^{+}\right)_{2}-\left(\mathrm{Ru}^{\mathrm{II}}(\mathrm{CN})_{6}{ }^{4-}\right) .8 \mathrm{H}_{2} \mathrm{O}\right]$ (space group P-1, $a=7.65 \AA, b=10.93 \AA, c=13.46 \AA, \alpha=70.26^{\circ}, \beta=75.08^{\circ}, \gamma=85.50^{\circ}$ ) have been structurally characterised by X-ray diffraction on single crystals. In both cases, the crystal is composed of $1-2 \mathrm{H}^{+}, \mathrm{M}^{\mathrm{II}}(\mathrm{CN})_{6}{ }^{4-}$ and water molecules. ${ }^{5 \mathrm{~b}}$ The study revealed that the cationic and anionic components are interconnected through both electrostatic interactions and H-bonding. In both cases, the crystal may be described as packed 2-D H-bonded networks offering channels which are filled with water molecules (Fig. 2). The structural investigation further demonstrated that both crystals were isostructural with small differences in unit cell dimensions and angles. Interestingly, the composite crystal has been also characterised by X-ray diffraction which revealed the conservation of crystallographic features, in particular crystallographic axis between the two crystalline phases and thus implying that the composite material was generated by a 3-D epitaxial growth. ${ }^{7}$ This is not surprising since the interconnection between consecutive anionic and cationic units is ensured by H-bonds which offers flexibility both in terms of distance and angle. ${ }^{\text {xiv }}$ 


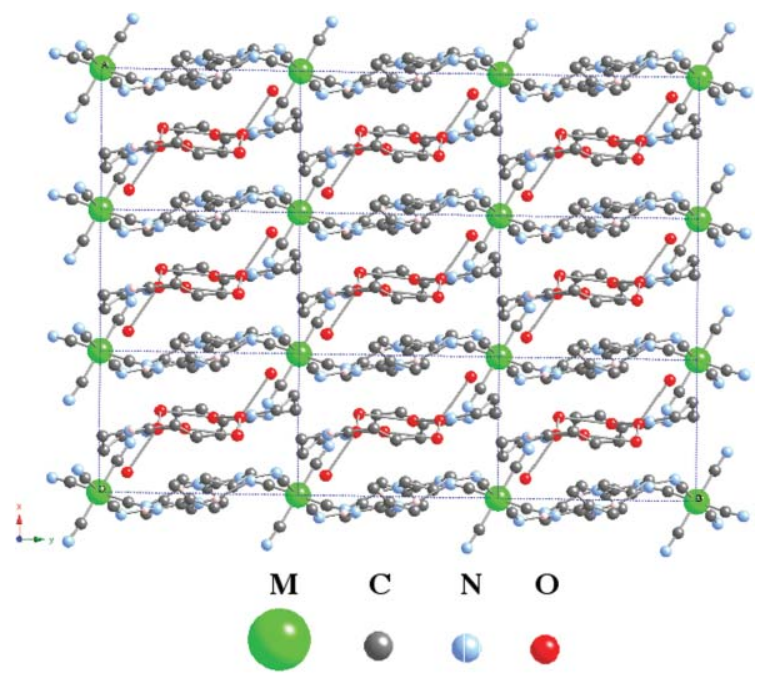

Figure 2

\section{Results and discussion}

The composite crystal (Fig. 1b) was formed by immersing the colourless crystal $\left[\left(1-2 \mathrm{H}^{+}\right)_{2}-\right.$ $\left.\left(\mathrm{Ru}^{\mathrm{II}}(\mathrm{CN})_{6}{ }^{4-}\right) .8 \mathrm{H}_{2} \mathrm{O}\right]$ (seed crystal) in a solution containing $\left[\left(1-2 \mathrm{H}^{+}\right)_{2}-\left(\mathrm{Fe}^{\mathrm{II}}(\mathrm{CN})_{6}{ }^{4-}\right) .8 \mathrm{H}_{2} \mathrm{O}\right] .{ }^{7}$

Owing to its brittleness, the composite crystal $(1.5 \times 2.5 \times 2.0 \mathrm{~mm})$, that was cut in order to be analysed, was rather difficult to handle, which excluded the use of microtome or grinding TEM sample preparation techniques. Hence, the TEM sample was thinned using a Field Ion Beam (FIB) microscope (FEI Nova Nanolab DualBeam ${ }^{\mathrm{TM}}$ FIB/STEM microscope at $30 \mathrm{kV}$ ). However, the sample was surprisingly resistant to electron irradiation. Indeed, no variation of the peak was observed when the probe was left on the same area of the sample for periods of more than 15 minutes. The area of interest was first identified with an optical microscope, using the colour difference between both crystals. Careful recording of the morphology and shape of the area of interest allowed relocating the area of the sample in the FIB/STEM as well as in the TEM. A foil of relatively high thickness of $5 \mu \mathrm{m}$ was first lifted out and then was placed on the $3 \mathrm{~mm}$ TEM half grid and thinned down to electron transparency. The TEM samples were analyzed with a Philips CM30 TEM equipped with a Noran Energy Dispersive Spectroscopy (EDS) Si detector. The analysis of the composition was performed in the STEM mode. Only the Fe-K and $\mathrm{Ru}-\mathrm{L}$ signals from $\left[\mathrm{Fe}(\mathrm{CN})_{6}\right]^{4-}$ and $\left[\mathrm{Ru}(\mathrm{CN})_{6}\right]^{4-}$ complex anions, were recorded. In comparison to reflection techniques $\left(1 \mu \mathrm{m}^{3}\right)$ such as Scanning Electron Microscopy, ${ }^{\mathrm{xv}}$ TEM yields a higher spatial resolution due to the reduced volume of interaction of the electrons with the material $\left(10^{-6} \mu \mathrm{m}^{3}\right)$. The sample was analyzed by EDS and successive recordings of Fe-K and $\mathrm{Ru}-\mathrm{L}$ peaks were carried out along a line across the interface (Fig. 3c). Variations of the 
count rate (Fig. 4a) and wt \% (The wt $\%$ of each element is calculated the following way: $w t \% \mathrm{Fe}=w t F e /(w t F e+w t R u))$ are ploted for Ru and Fe (Fig. 4b).

Whereas the interface between the two crystalline zones appears as a straight line when observed by optical microscope at 8,5 magnification (Fig 1b), FIB/STEM and TEM observations revealed defects such as holes and pores all over the composite crystal (Fig 3). This heterogeneity may be caused by the loss of water molecules during the observation made under high vacuum $\left(10^{-7}\right.$ torr $)$.

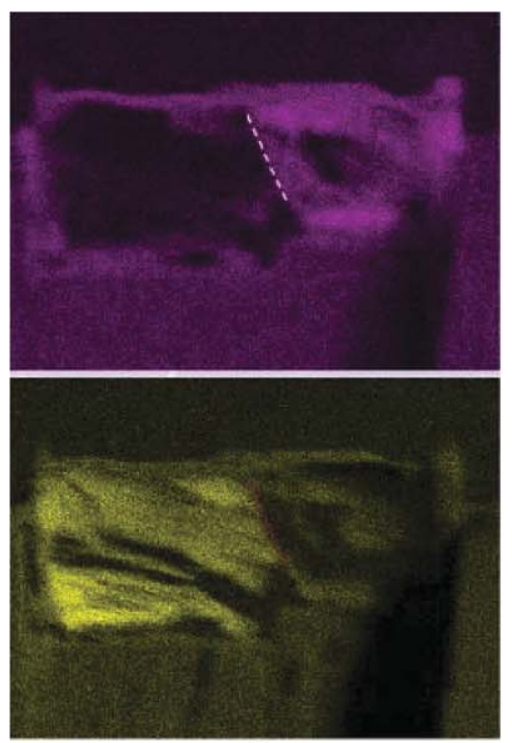

a)

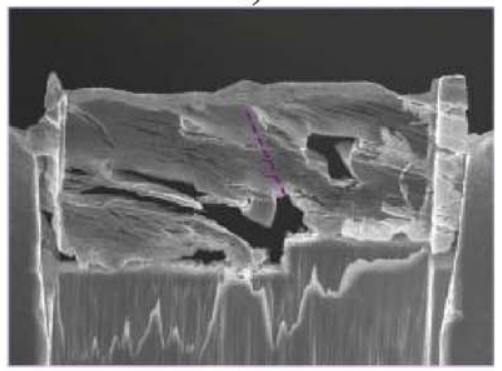

b)

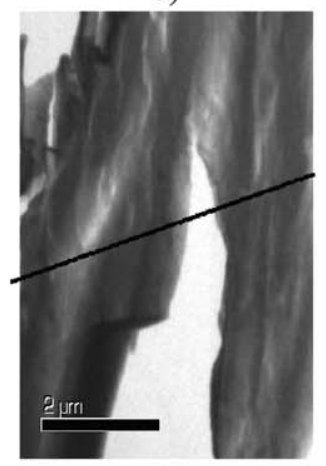

c)

Figure 3 
Since the interface cannot be directly observed during the TEM study, it was localized through EDS maps based on the observation of $\mathrm{Fe}^{2+}$ and $\mathrm{Ru}^{2+}$ metal centres using FIB/STEM (Fig. 3).

The chemical distribution of $\mathrm{Fe}^{2+}$ and $\mathrm{Ru}^{2+}$ cations complexed by six cyanide ligands across a thin section of the interface was analyzed by Transmission Electron Microscopy (TEM) and Electron Dispersive Spectrometry (EDS). The technique clearly revealed that signals corresponding to $\mathrm{Fe}^{2+}$ and $\mathrm{Ru}^{2+}$ extend on both sides beyond the interface. This observation implies that both $\left[\mathrm{Fe}(\mathrm{CN})_{6}\right]^{4}$ and $\left[\mathrm{Ru}(\mathrm{CN})_{6}\right]^{4}$ species are present in opposite directions with respect to the interface over a distance of about $0.7 \mu \mathrm{m}$ (Fig. 4). The observed data shows local variations for both curves (see fig. $4 \mathrm{a}$ and $4 \mathrm{~b}$ ) which can be related to the porous nature (presence of defects as seen in fig. 3) and to the likely roughness of the materials surface as these affect the feature of the spectra. ${ }^{\mathrm{xvi}}$

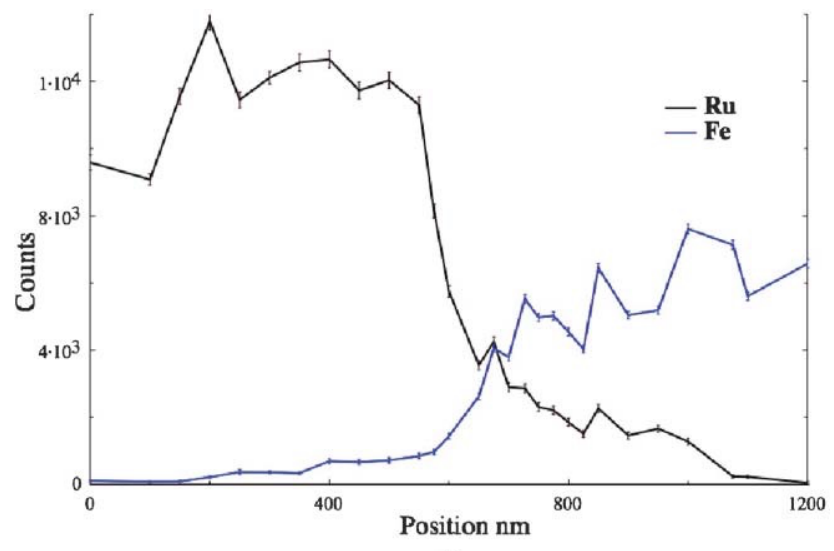

a)

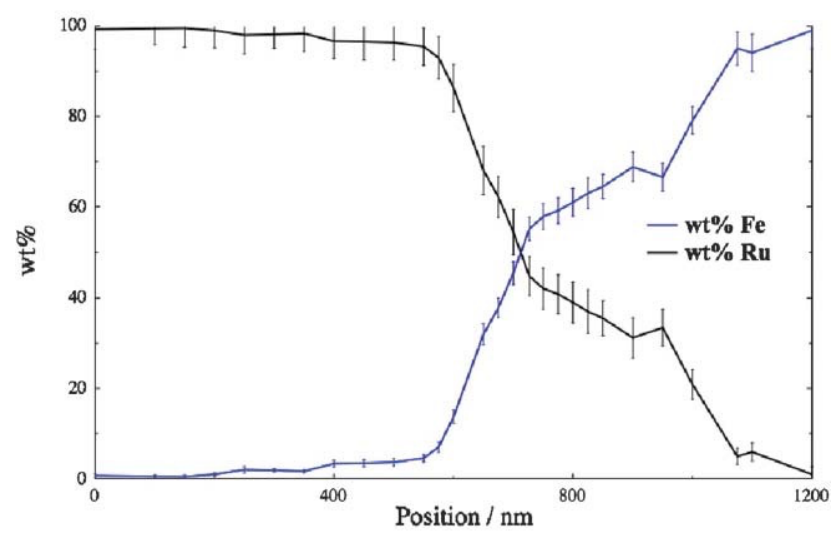

b)

Figure 4

The main question to be discussed here is why and how the two species are distributed over such a large distance. In other terms, why such a diffuse interface is obtained. Since the growth of the composite crystal is achieved in solution, one may envisage three possibilities. (i) The 
surface partial dissolution of the seed crystal, governed by the kinetics of dissolution, would release $\left[\mathrm{Ru}(\mathrm{CN})_{6}\right]^{4-}$ anions and $1-2 \mathrm{H}^{+}$cations into the aqueous phase containing $1-2 \mathrm{H}^{+}$and $\left[\mathrm{Fe}(\mathrm{CN})_{6}\right]^{4-}$ species This is reasonable since both the anionic $\left[\mathrm{Ru}(\mathrm{CN})_{6}\right]^{4-}$ and cationic $\left(1-2 \mathrm{H}^{+}\right)$ components are soluble in water, although to a lower extent for the organic partner. Owing to the rather low concentration of $\left[\mathrm{Ru}(\mathrm{CN})_{6}\right]^{4-}$ with respect to $\left[\mathrm{Fe}(\mathrm{CN})_{6}\right]^{4-}$, the epitaxial growth of the subsequent crystalline layers would mainly be achieved by $\left(1-2 \mathrm{H}^{+}\right)$and $\left[\mathrm{Fe}(\mathrm{CN})_{6}\right]^{4-}$ species. The distribution of the two anionic complexes around the interface would then result from the roughness of the surface of the seed crystal. In favour of this, the observation of a solid solution previously obtained upon combining the dicationic $1-2 \mathrm{H}^{+}$with an equimolar mixture of $\left[\mathrm{Ru}(\mathrm{CN})_{6}\right]^{4--}$ and $\left[\mathrm{Fe}(\mathrm{CN})_{6}\right]^{4-}{ }^{7}$ This combination leads to the formation of a crystalline material displaying an intermediate colour as well as cell parameters when compared to pure crystals obtained in the presence of $\left[\mathrm{Ru}(\mathrm{CN})_{6}\right]^{4-}$ or $\left[\mathrm{Fe}(\mathrm{CN})_{6}\right]^{4-}$. The obtention of this solid solution explains the variability of the phase interface with fractional composition $\left(\left[\left(1-2 \mathrm{H}^{+}\right)_{2}-\left(\mathrm{Ru}(\mathrm{CN}){ }_{6}^{4-}\right.\right.\right.$ )$\left.\left._{\mathrm{x}}\left(\mathrm{Fe}(\mathrm{CN})_{6}{ }^{4-}\right)_{1-\mathrm{x} .} .8 \mathrm{H}_{2} \mathrm{O}\right]\right)$ at the interface.

(ii) The second possibility could be the formation of crystalline aggregates or nanocrystals of $\left[\left(1-2 \mathrm{H}^{+}\right)_{2}-\left(\mathrm{Fe}(\mathrm{CN})_{6}{ }^{4-}\right) .8 \mathrm{H}_{2} \mathrm{O}\right]$ in solution and their subsequent coalescence with the seed crystal. In that case, the observed distribution at the interface would result from the match between the size of aggregates and cavities at the surface of the seed crystal.

(iii) Finally, the third alternative would be the diffusion of molecular species within the already formed composite crystal. Obviously, the latter diffusion mechanism in the crystalline phase may take place no matter how the composite crystal is generated (by dissolutionrecrystallisation or by crystals coalescence).

Dealing with the diffusion process in the crystalline phase, it is worth noting that the interactions between anionic and cationic components are electrostatic in nature and take place by establishment of reversible H-bonds between the acidic hydrogen atoms belonging to the organic tectons $1-2 \mathrm{H}^{+}$and the nitrogen centres of the cyanide ligands of $\left[\mathrm{M}(\mathrm{CN})_{6}\right]^{4-}(\mathrm{M}=\mathrm{Ru}$ or $\mathrm{Fe}$ ). As stated above, the connectivity through H-bonding leads to the formation of 2-D sheets. The packing of the latter generates channels, which are occupied by water molecules (Fig. 2). Owing to the rather small size of both the cation (length of $11.1 \AA$ and width of $c a 2 \AA$ ) and the anion (octahedral geometry with a diameter of $6.2 \AA$ ), one may imagine the motion of these species within the lattice. These movements may further be favoured by the presence of mobile water molecules. Furthermore, the presence of holes and defects may also increase the mobility of the molecular species. 


\section{Conclusion}

Using microscopic techniques such as TEM and EDS analysis, we have observed the formation of a diffuse interface extended over a range of $c a 0.7 \mu \mathrm{m}$ between two molecular crystalline systems obtained upon 3-D epitaxial growth of a crystalline phase at the surfaces of a seed crystal (composite crystal). We proposed three possible processes which may explain the distribution of molecular species at the interface. These mechanisms could be dissolutionrecrystallisation, coalescence of aggregates or nanocrystals with the seed crystal and finally the diffusion of molecular units with the crystalline phase. It might be of interest to reduce to porosity of the bulk of both crystals, by reducing the rate of the crystal growth by lowering the growth temperature or concentration of the components. However, owing to the brittleness of the material, no other investigations have been carried out.

Acknowledgement: We thank Université Louis Pasteur, Institut Universitaire de France, Ministry of Education and Research and CNRS for financial support.

\section{Notes and references}

i J.-M. Lehn, Supramolecular Chemistry, Concepts and Perspectives, VCH, Weinheim, 1995.

ii a) M. Simard, D. Su, J. D. Wuest, J. Am. Chem. Soc., 1991, 113, 4696. b) S. Mann, Nature, 1993, 365, 499.

iii M. W. Hosseini, Cryst. Eng. Comm., 2004, 6, 318; M. W. Hosseini, Chem. Comm., 2005, 5825 .

iv a) C. Janiak, Dalton Trans. 2003, 295, 2410; b) M. W. Hosseini, Acc. Chem. Res. 2005, 38, 313 .

v a) S. Ferlay, O. Félix, M. W. Hosseini, J.-M. Planeix, N. Kyritsakas, Chem. Comm., 2002, 702 ; b) S. Ferlay, V. Bulach, O. Félix, M. W. Hosseini, J.-M. Planeix, N. Kyritsakas, Cryst. Eng. Comm., 2002, 4, 447; c) S. Ferlay, R. Holakovsky, M. W. Hosseini, J-M. Planeix, N. Kyritsakas Chem. Comm., 2003, 1224; d) C. Paraschiv, S. Ferlay, M. W. Hosseini, V. Bulach, J-M. Planeix, Chem. Comm., 2004, 2270.

vi a) C. Bosshard, K. Sutter, P. Prêtre, J. Hulliger, M. Flörsheimer, P. Kaatz, P. Günter, Organic Nonlinear Optical Materials, Gordon and Breach Science Publishers: 
Switzerland, Postfach, 1995, Vol.1; b) C. B. Aakeröy, A. M. Beatty, Cryst. Eng. Comm. 1998, 1, 39; c) J. Fraxedas Adv. Mater. 2002, 14, 1603.

vii a) S. Ferlay, M. W. Hosseini, Chem. Comm., 2004, 788; b) P. Dechambenoit, S. Ferlay, M. W. Hosseini, Cryst. Gr. Des., 2005, 5, 2310.

viii a) J. C. MacDonald, P. C. Dorrestein, M. M. Pilley, M. M. Foote, J. L. Lundburg, R. W. Henning, A. J. Schultz, J. L. Manson, J. Am. Chem. Soc., 2000, 122, 11692 ; b) J.C. Noveron, M. S. Lah, R. E. Del Sesto, A. M. Arif, J. S. Miller, P. J. Stang, J. Am. Chem. Soc., 2002, 124, 6613; c) T-J. M. Luo, J. C. MacDonald, G. T. R. Palmore, Chem. Mater., 2004, 16, 4916.

ix C. L. Briant, Materials Interfaces: Atomic-level structure and Properties. Eds. Dieter Wolf and S. Yip, Chapman and Hall, London, 1992.

x W. D. Kingery, H. K. Bowen, D. R. Uhlmann, Introduction to ceramics Second edition. Wiley, New-York, 1976.

xi C. J. Brinker, A. J. Hurd, P. R. Schunk, G. C. Frye, C. S. Ashley, L. Esquivas, J. Non Cryst. Solids, 1992, 424, 147.

xii R. Mc Pherson, Surf. Coat. Technol., 1989, 173, 39.

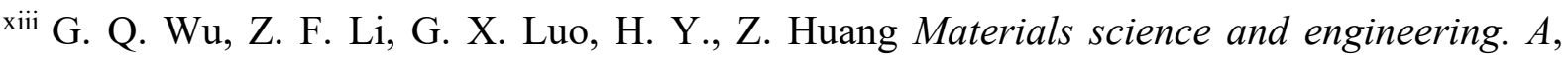
2007 , in the press.

${ }^{\text {xiv }}$ R. Taylor, O. Kennard Acc. Chem. Res., 1984, 17, 320.

xv P. Dalbeck, M. Cusak Cryst. Gr. Des., 2006, 6, 2558.

${ }^{x v i}$ a) R. Gauvin, E. Lifshin, X-ray microanalysis. Microchim. Acta, 2004, 145, 41 ; b) P. Bush, U. Förster, Fresenius J. Anal. Chem., 1997, 358, 155.

\section{Figure captions:}

Figure 1: (a) Representation of the bisamidinium cation 1-2 $\mathrm{H}^{+}$and (b) pictures of a cocrystal formed upon 3-D epitaxial growth of $\left[\left(1-2 \mathrm{H}^{+}\right)_{2}-\left(\mathrm{Fe}^{\mathrm{II}}(\mathrm{CN})_{6}{ }^{4-}\right) .8 \mathrm{H}_{2} \mathrm{O}\right]$ (orange) on a seed crystal of $\left[\left(1-2 \mathrm{H}^{+}\right)_{2}-\left(\mathrm{Ru}^{\mathrm{II}}(\mathrm{CN})_{6}{ }^{4}\right) .8 \mathrm{H}_{2} \mathrm{O}\right]$ (colourless).

Figure 2: A projection along [001] direction of a portion of the $\mathrm{X}$-ray structure of the 2-D network $\left[\left(1-2 \mathrm{H}^{+}\right)_{2}-\left(\mathrm{M}(\mathrm{CN})_{6}{ }^{4-}\right) .8 \mathrm{H}_{2} \mathrm{O}\right](\mathrm{M}=\mathrm{Ru}, \mathrm{Fe}) . \mathrm{H}$ atoms are not represented for sake of clarity.

Figure 3: Localisation of the interface by EDS maps (Fe in purple, Ru in yellow) (a), the interface is indicated by a dashed line (b) and a medium magnification TEM image of the cocrystal (c), the interface is indicated by the dark straight line across the crystal.

Figure 4: a) Count rate for Fe-K and Ru-L (a) and wt \% variation (b) across the interface. 


\section{Legend to graphical abstract}

The interface of a molecular composite crystal made by epitaxial growth of crystalline layers on a seed crystal was studied by both TEM and FIB/STEM microscopies. Distribution of the components revealed a diffuse interface between the two isostructural phases extending over ca $0.7 \mu \mathrm{m}$. 